\title{
A new Journal for telecommunications with an added purpose
}

\author{
Peter Gerrand \\ Managing Editor
}

What is this new journal? The Australian Journal of Telecommunications and the Digital Economy (ajTDE) is the reincarnation of the Telecommunications Journal of Australia (TJA), under the guidance of essentially the same Editorial Board - give and take a few distinguished members - who had moved the traditional 'print and post' version of TJA (published since June 1935) to its exclusively online version (from November 2007 to June 2013).

ajTDE - with guarantees of funding and editorial independence from its new publisher, TelSoc - is designed to replace and exceed TJA as the authoritative Australian journal providing timely peer-reviewed articles on new developments in telecommunications technology, policy and user experiences, for a multidisciplinary readership.

But the new Journal will place more emphasis on applications of telecommunications to the digital economy and the society it serves. Why?

Firstly, the global digital economy is sweeping up most forms of commerce into its path, offering massive opportunities in new revenues and in the creation of high-value, diverse employment. But it is also potentially threatening to national economies which are too slow to change. Australia must urgently position itself to maximise its opportunities and its contributions in health, education, finance, entertainment, media and communications, design, retail, public administration, and in security and environmental monitoring, to name the most obvious sectors. Phil Ruthven's 'A snapshot of Australia's digital future to 2050' (Ruthven 2012) conservatively estimates that by that mid-century year, the digital economy will contribute eight times more revenue than the $\$ 131$ billion it contributed in 2012, provided it is underpinned by universal broadband at internationally competitive speeds and pricing, i.e. an upgradeable NBN starting at 100 Mbps download capacity. A telling quotation from the Ruthven report is "Today, even with our current 'pony express' form of broadband, the value of the Internet to the Australian economy rivals iron-ore exports" (Ruthven 2012: 9). 
Of course a second fundamental benefit of the National Broadband Network (NBN) depends upon its ubiquity: its potential to make high-value jobs in the digital economy possible across the length and breadth of Australia, revitalising many country towns, and also redistributing some of the projected population growth away from our already congested capital cities.

The second reason for giving explicit attention to telecommunications applications and services for the digital economy is as follows. Bitter political divisions over the NBN over the past four years have shown that such a huge public investment in infrastructure will not gain overwhelming public endorsement - enough to ensure bipartisan political support - unless the intended benefits to the general community are very widely understood. In the case of the NBN, its major benefits can be summarised as growing a diverse and internationally competitive digital economy - which will simply not happen to the broad benefit of society without first researching and understanding the digital economy's potential, and developing a raft of well-crafted additional public policies to best enable it.

That is why the digital economy will be a key focus area for this new Journal: publishing the best research to better understand the digital economy's potential, and contributing well-crafted public policy ideas to ensure that its benefits become widespread, affordable and socially equitable for the whole community.

\section{Reference}

Ruthven, Phil. 2012. A snapshot of Australia's digital future to 2050, IbisWorld, June 2012, available at http://www-07.ibm.com/ibm/au/digitalfuture/

Cite this article as: Gerrand, Peter. 2013. 'A new journal for telecommunications with an added purpose'. Australian Journal of Telecommunications and the Digital Economy 1 (1): pp.18.1 18.2. DOI: $10.7790 / a j t d e . v 1 \mathrm{n} 1.18$ Available from: http://telsoc.org/journal 